\title{
História e Ética na Conservação e na Restauração de Monumentos Históricos
}

Beatriz Mugayar Kühl*

\section{Resumo}

O artigo aborda questões teóricas da conservação e restauração dos monumentos históricos e sua relação com a deontologia profissional. Com esse intuito são examinadas, em linhas gerais, as transformações por que passaram as teorias de restauro e conservação, destacando-se os preceitos formulados por Alois Riegl e Cesare Brandi. Analisam-se também as tendências contemporâneas, com o intuito de averiguar os princípios gerais que deveriam guiar as intervenções. Procura-se enfatizar a relevância da reflexão teórica para enfrentar os problemas em toda a sua complexidade. Mostra-se a importância essencial do entendimento dos monumentos históricos também como documentos históricos, de modo a fundamentar uma prática profissional baseada em sólida deontologia, como meio eficiente e responsável de preservar os aspectos materiais, históricos, formais e simbólicos dos monumentos.

Palavras-chave: Monumentos históricos. Teoria da restauração e da conservação. Deontologia profissional.

\section{History and Ethics in Conservation and Restoration of Historic Monuments}

The article deals with theoretical problems associated with the conservation and restoration of historic monuments and their relation with professional deontology. The historical transformations undergone by restoration and conservation theories are examined in broad lines, emphasizing the importance of the principles formulated by Alois Riegl and Cesare Brandi. The contemporary tendencies are also analyzed in order to verify the principles that should guide the interventions. The author seeks to place an emphasis on the relevance of theoretical reflection in order to face problems in their full intricacy. The article shows that the perception of historic monuments also as historic documents is essential to a professional practice based on a solid deontology. That is considered to be an efficient and responsible means of preserving the material, historic, formal and symbolic values of monuments. 
Keywords: Historic monuments. Conservation and restoration theories. Professional deontology.

A atuação em bens legados por épocas passadas, desde que passou a assumir uma conotação cultural - principalmente a partir da segunda metade do século XVIII -, sempre esteve ligada, através de laços mais ou menos estreitos, às variadas correntes historiográficas ou visões sobre a estética nos diversos períodos ${ }^{1}$.

Essa, porém, não é a abordagem escolhida para este texto. Serão tratados temas vinculados à importância da história e da historiografia para quem atua com bens culturais. Busca-se evidenciar como isso se relaciona à ética das várias profissões e competências necessárias ao campo, de modo a conduzir a uma sólida deontologia profissional. Essa escolha foi feita em função da formação e da área de atuação da autora - arquiteta, professora de história da arquitetura e de teoria da restauração na FAUUSP -, que depende da historiografia, em especial da historiografia da arte e da arquitetura, como instrumentos essenciais de trabalho. Essas considerações são apresentadas longe de se pensar que a historiografia em geral, e a da arte e da arquitetura em particular, devam ser tratadas apenas como instrumento para a atuação em monumentos históricos, ou que esse seja seu objetivo principal. Ao contrário, são campos disciplinares autônomos a pleno título. $\mathrm{O}$ que se quer enfatizar é algo diverso: a historiografia pode prescindir da conservação e da restauração; já as ações de preservação não deveriam prescindir, jamais, da história e historiografia, e os profissionais atuantes na preservação, mesmo não sendo todos historiadores, deveriam possuir uma "visão histórica" e sólida formação no campo - para entender e respeitar aquilo que é relevante do ponto de vista histórico-documental -, pois a ausência de uma consciência histórica pode trazer, e na maioria dos casos traz, conseqüências da maior gravidade nas ações sobre os bens culturais. Neste trabalho serão abordados, em especial, problemas relativos à preservação arquitetônica; no caso, por ser campo de formação da autora, com o qual tem maior afinidade, mas sem o intuito de dar uma indevida primazia a esse tipo de manifestação, nem, tampouco, por considerar a preservação arquitetônica como algo isolado, distinto da preservação dos bens culturais como um todo. Considera-se, antes, que a preservação deva seguir uma unidade de metodologia 
para todos os tipos de manifestações, variando-se, na prática, os meios postos em ação para intervir.

Na concepção contemporânea alargada sobre os bens culturais, a tutela não mais se restringe apenas às "grandes obras de arte", como ocorria no passado, mas se volta também às obras "modestas" que com o tempo assumiram significação cultural. Nesse sentido, é prudente esclarecer que se utiliza a expressão monumentos históricos, não como obras grandiosas isoladas, mas vinculada ao sentido etimológico de monumento e como interpretada por Riegl, ou seja: como instrumentos da memória coletiva e como obras de valor histórico que, mesmo não sendo "obras de arte", são sempre obras que possuem uma configuração, uma conformação.

Serão apresentados a seguir, de modo conciso, alguns acenos sobre as transformações por que passaram as noções de restauro e as tendências teóricas atuais, para evidenciar que a preservação de bens culturais, tal como entendida hoje, tem raízes longínquas. É possível detectá-las no século XV, quando, de forma paulatina, as intervenções em obras de épocas passadas deixam de ter como moventes questões de ordem essencialmente prática e utilitária e começam a ter motivação cultural. A partir de finais do século XVIII a preservação vai se sistematizar, assumindo, de forma gradativa, uma maior autonomia e consolida-se como campo disciplinar autônomo principalmente a partir do século $X X^{2}$. Existem, portanto, preceitos, princípios teóricos que fundamentam esse campo e que se baseiam em pelo menos dois séculos de produções teóricas associadas a experiências práticas relevantes. Deve-se, porém, sempre ter aproximação crítica em relação a qualquer campo do saber e as interpretações podem e devem divergir. No entanto, não se pode ignorar a existência da discussão e as consistentes contribuições que existem na área, que permitem que se circunscreva o tema de maneira pertinente, oferecendo importantes instrumentos para a reflexão.

As intervenções feitas em edifícios já existentes foram, ao longo do tempo, voltadas, em geral, para sua adaptação às necessidades da época e ditadas por exigências práticas e de uso. No entanto, noções que floresceram, isolada e esporadicamente, a partir do Renascimento e amadureceram entre os séculos XV e XVIII, foram posteriormente conjugadas na formação das vertentes teóricas da restauração: o respeito pela matéria original; a idéia de reversibilidade e distinguibilidade da intervenção; a importância da documentação e de uma 
metodologia científica; o uso como um meio de preservar os edifícios e não como a finalidade da intervenção; o interesse por aspectos conservativos e de mínima intervenção; a noção de ruptura entre passado e presente. Preponderantes foram ainda o despontar do lluminismo, os debates gerados pelas aceleradas transformações decorrentes da Revolução Industrial e pelas destruições após a Revolução Francesa. Assim, a preservação de monumentos históricos assume significado essencialmente cultural, entendido, neste texto, como pautado nos valores formais, históricos, simbólicos e memoriais, em contraposição às ações de cunho prático.

Esse processo de maturação foi combinado a formulações teóricas e a experiências sistemáticas, de inventários e intervenções, que se desenrolaram no século XIX, com repercussão também na legislação de alguns países, verificando-se várias vertentes, tais como: a que almejava atingir um estado completo idealizado da obra, normalmente tendo como objetivo a unidade de estilo, não importando se, para tanto, tivessem que ser sacrificadas várias fases da obra e feitas substituições maciças, cujo mias notório representante foi Eugène $E$. Viollet-le-Duc; a que preconizava respeito absoluto pela matéria original - encabeçada por John Ruskin e William Morris - aconselhando manutenções periódicas para prolongar o mais possível a vida do edifício, mas admitindo a possibilidade de perda de um dado bem. As experiências díspares e, mesmo, antitéticas (que encontravam representantes em suas várias versões, concomitantemente, em diversos países), foram reformuladas no final do século XIX, em especial por Camillo Boito, consolidando uma via que se contrapôs à prática difusa de tentativas de voltar a um suposto estado original, unidade de estilo, ou estado anterior qualquer - que acarretou a destruição ou deturpação de muitos documentos históricos -, preconizando o respeito pela matéria original, pelas marcas da passagem do tempo e pelas várias fases da obra, além de recomendar a mínima intervenção e, no caso de acréscimos, a distinguibilidade da ação contemporânea, para que esta última não fosse confundida com aquilo que subsistia da obra, o que poderia levar o observador ao engano de considerá-la como antiga.

A ênfase no valor documental dos monumentos se firmaria no século $X X$. Contribuições relevantes foram dadas por Alois Riegl, na virada do século XIX para o XX, oferecendo meios inovadores tanto para a teoria quanto para a prática da preservação dos monumentos históricos, abarcando aspectos normativos (no caso, 
na Áustria), e elaborando análises agudas sobre o papel dos monumentos históricos e suas formas de apreensão por uma dada sociedade ${ }^{3}$. Riegl deu passos fundamentais para consolidar a preservação de bens culturais como um campo disciplinar autônomo ${ }^{4}$, que deixou de ser apenas um "auxiliar" da história da arte (assim como também contribuiu para a consolidação da própria história da arte como um campo autônomo em relação à "história geral"), passando a assumir características próprias, podendo, por sua vez, oferecer contribuições para a própria historiografia e para a criação artística contemporânea. Elaborou proposições prospectivas, que permanecem válidas ainda hoje, contendo elementos que podem ser continuamente explorados.

De enorme interesse são suas colocações na obra O Culto Moderno dos Monumentos, de 1903. Esse texto de Riegl, faz parte de um projeto de organização legislativa para a conservação na Áustria, sendo composto de três partes: a primeira, justamente $O$ Culto, que é uma discussão teórica que fundamenta a proposta de lei; a segunda, é o projeto de lei para a tutela dos monumentos; a parte final é composta pelas disposições para aplicação da lei (cuja implementação seria concretizada décadas mais tarde, com outra conformação) ${ }^{5}$.

As propostas de Riegl tendiam a se distanciar da discussão sobre monumentos históricos fundamentada apenas em considerações histórico-artísticas, como prevalecera até então, passando a considerar também as formas de recepção, de percepção e de fruição dos monumentos, através dos "valores" por ele explicitados no Culto. ${ }^{6}$ Ademais, para Riegl, monumentos históricos eram não apenas as "obras de arte", mas qualquer obra humana com certa antigüidade (para ele, qualquer obra com mais de sessenta anos) ${ }^{7}$, contrapondo-se assim às políticas de preservação que se voltavam apenas aos objetos de excepcional relevância histórica e artística.

O "valor de antigüidade" - que depende da preservação escrupulosa das várias estratificações, inclusive das marcas da passagem do tempo - era o mais prezado por Riegl e sobre esse valor fundamentam-se suas propostas para a nova legislação, que tinha por intuito promover uma tutela difusa para assegurar a preservação de ampla gama de testemunhos relevantes de épocas passadas. Neste ponto é importante esclarecer que a análise apresentada por Riegl no Culto, serve de substrato para a elaboração do projeto de lei, mas de modo algum, na atuação sobre os monumentos, Riegl considerava que os outros "valores" devessem ser aplicados, de modo alternado ou indistinto, dependendo da situação; sua proposta 
de lei é baseada essencialmente no respeito ao valor de "antigüidade"8.

A futura tutela dos monumentos deve ser baseada sobre o culto do valor de antigo, que se manifesta com a existência dos traços de antigüidade. A maior preocupação da futura tutela dos monumentos deve ser voltada para a conservação desses traços e, por isso, devem cair inevitavelmente os postulados da originalidade e da unidade estilística, ligados ao culto do valor histórico e do valor de novidade, que objetivam, ambos, à sua eliminação [dos traços de antigüidade].

Esse era um modo de fundamentar a tutela dos monumentos, que não mais teria como objetivo, como predominara até então na práxis austríaca, a unidade de estilo. Ou seja, o interesse da tutela não se volta à retomada de "formas" antigas e desconsideração das várias estratificações dos edifícios, mas tem por objetivo respeitar escrupulosamente o documento histórico e os próprios traços de antigüidade, das marcas da passagem do tempo.

O valor artístico era por ele considerado por demasiado mutável, pois variava pela medida em que satisfazia o Kunstwollen de uma dada época, algo que não é formulado de maneira absoluta e jamais o poderia ser, pois muda de indivíduo para indivíduo, de sociedade para sociedade e de momento para momento. Desse modo, se não existe um valor artístico eterno, mas somente um valor relativo, o valor artístico de um monumento não é um valor de rememoração, mas um valor atual, de contemporaneidade. A conservação deve, pois, levar isso em conta, por se tratar de valor flutuante. Desse modo, o culto do "valor de antigüidade" era, segundo o autor, de grande atração, justamente por ser mais inclusivo, mais perene, e que respeita integralmente o documento histórico, as obras de toda e qualquer fase da produção humana e as várias estratificações de uma mesma obra.

Riegl foi ainda um dos primeiros a evidenciar que as atuações voltadas à preservação dos monumentos históricos (e todos os problemas a ela ligados) não podem ser entendidas em sentido absoluto, não existindo uma única solução universalmente válida, mas comporta várias soluções, de pertinência relativa ${ }^{9}$, mesmo em relação a um dado presente histórico. Mas isso não significa que a ação seja arbitrária, pelo contrário. Esse tema será explorado mais adiante.

Em meados do século $X X$ foram feitas várias novas proposições no campo da restauração, que surgiram também em conseqüência das destruições da $2^{\mathrm{a}}$ Guerra Mundial, evidenciando os reduzidos instrumentos teóricos até então empregados para se entender a realidade figurativa dos monumentos. As contribuições da Estética não haviam sido levadas suficientemente em conta, não sendo empregados 
os meios conceituais disponíveis para abordar obras e extensas áreas devastadas, tornando-se evidente a inadequação de se trabalhar com "neutros" no completamento de edifícios, ou no tratamento de conjuntos urbanos, como se fizera e propusera naquela primeira metade do século.

Foram de relevância (e permanecem atuais) textos escritos desde os anos 1940, a exemplo dos de Cesare Brandi, Roberto Pane, Renato Bonelli e Paul Philippot, atingindo-se certa posição de consenso internacional na Carta de Veneza, de 1964. Houve buscas paralelas que convergiram em alguns temas, oferecendo meios para a crítica e aprofundamento recíprocos. Autores filiados ao chamado "restauro crítico" ${ }^{10}$, tais como Bonelli e Pane, alicerçam suas posições nas análises das transformações históricas por que passaram as teorias de restauração, reformulando-as e articulando-as a outras enunciações da época, tais como as de Brandi, que, por sua vez, fundamenta suas proposições essencialmente através da Estética e da História.

Deu-se maior ênfase aos valores formais do que no período anterior - em que predominou o valor documental da obra -, sem desrespeito, porém, aos aspectos históricos e às várias fases por que passou o monumento ao longo de sua vida. As variadas experiências contribuíram, através de um lento processo de amadurecimento ao longo dos séculos e de um conjunto de experiências, que não foram nem homogêneas nem lineares, para fundamentar noções ligadas ao restauro que permanecem atuais. A restauração deveria ser entendida, na definição de Brandi - que fundou o Instituto Central de Restauração (ICR), em Roma, em 1939 e o dirigiu por duas décadas -, como "o momento metodológico do reconhecimento da obra de arte, na sua consistência física e na sua dúplice polaridade estética e histórica, com vistas à sua transmissão ao futuro" ${ }^{11}$.

O restauro é, pois, baseado no reconhecimento que se faz da obra de arte como tal e enquanto documento histórico, e, portanto, como dado cultural, fundamentando-se no "reconhecimento" da teoria brandiana, na análise da conformação da obra em seus aspectos físicos e como imagem figurada, e de sua transformação ao longo do tempo, através de instrumentos de reflexão oferecidos pela filosofia e historiografia da arte, crítica e estética.

O "reconhecimento" da teoria de Brandi é uma operação, com raízes na fenomenologia ${ }^{12}$, profunda e complexa de deixar-se penetrar na obra de arte e no processo que a produziu, examinando-a em sua plenitude formal, buscando, por 
assim dizer, sua realidade ontológica. As formulações de Brandi retomam certas proposições, através de uma ascendência kantiana, explorando formulações com repercussões na estética e historiografia de variados autores, tais como Benedetto Croce, Jean-Paul Sartre, Martin Heidegger, Edmund Husserl, Georg Wilhelm Friedrich Hegel. Através do "reconhecimento" brandiano, como exposto em Celso o della Poesia ${ }^{13}$, e analisado por Paolo Antinucci, o artista trabalha com a formulação do objeto através do seguinte processo: após neutralização existencial do objeto real, este último torna-se fenômeno, imagem funcionalizada na consciência, como parte do processo cognitivo do artista, que seleciona nesse fenômeno os aspectos ópticos que fornecem a possibilidade para que se forme na consciência do artista; nesse ponto, aninha-se o processo de constituição do objeto para o qual se busca uma forma adequada, para torná-lo palpável e transmitir uma dada imagem. O artista não formula o objeto de modo que esse pensamento ou objetivo sejam imediatamente legíveis, porém a consciência de quem frui é por si capaz de perceber, através da lógica profunda da obra, sua própria estrutura ontológica. Por isso, como nota Antinucci, para Brandi uma obra de arte não se compreende, se reconhece, pois o que se reconhece é o inteiro processo que a produziu. Esse modo particular do existir da obra, que Brandi denomina "astanza", é o ser no mundo do objeto, que se repete toda vez que a obra é reconhecida, havendo possibilidade contínua do reconhecimento ao longo do tempo. E é esse reconhecimento que faz da obra de arte uma obra de arte, processo que não é imediato, mas extremamente complexo, reconhecendo o objeto na plenitude de sua herança formal, de sua estrutura ontológica ${ }^{14}$.

Esse processo do "reconhecimento" da obra de arte é, segundo Brandi, "reconhecimento duplamente singular, seja pelo fato de dever ser efetuado toda vez por um indivíduo singular, seja por não poder ser motivado de outra forma a não ser pelo reconhecimento que o indivíduo singular faz dele"15, em razão do próprio processo descrito acima. O que não significa, como querem alguns, que a intervenção da restauração seja, por isso, um ato individual, em que cada um faz o que quer, tornando-o um ato arbitrário. Pelo contrário, todo o esforço do autor voltase a afastar a restauração do empirismo e da arbitrariedade com intuito de vinculá-la ao processo histórico-crítico ${ }^{16}$. Pela própria definição de Brandi, a metodologia da restauração conduz ao trabalho multidisciplinar (consistência física e dúplice polaridade estética e histórica), mesmo que a parte operacional seja executada por 
uma única pessoa. Afastar do empirismo, vincular à crítica de arte, a isso leva a definição de Brandi, pois a restauração não é apenas o reconhecimento, é o "momento metodológico do reconhecimento da obra de arte, na sua consistência física e na sua dúplice polaridade estética e histórica, com vistas à sua transmissão ao futuro", metodologia que é vinculada à crítica de arte, estética e história:

\footnotetext{
Por isso, definindo a restauração como o momento metodológico do reconhecimento da obra de arte como tal, a reconhecemos naquele momento do processo crítico em que, tão-só, poderá fundamentar a sua legitimidade; fora disso, qualquer intervenção sobre a obra de arte é arbitrária e injustificável. Além do mais, retiramos para sempre a restauração do empirismo dos procedimentos e a integramos na história, como consciência crítica e científica do momento em que a intervenção de restauro se produz ${ }^{17}$.
}

Prova disso é também a própria organização que Brandi imprimiu ao ICR:

A organização do Instituto, sendo baseada no conceito de restauração como crítica filológica, segundo o qual se recomenda restaurar inicialmente aquilo que resta de uma obra de arte, a direção do Instituto foi confiada não a um restaurador, mas a um historiador da arte, secundado por um comitê técnico, composto de arqueólogos, de historiadores da arte e de críticos de $\operatorname{arte}^{18}$.

O autor continua descrevendo os vários serviços e laboratórios do Instituto, que envolve profissionais de variadas formações, evidenciando ainda mais o caráter multidisciplinar e jamais individual e arbitrário da restauração. Muitos consideram as formulações de Brandi excessivamente teóricas, que a Teoria foi concebida como texto filosófico, desvinculada da prática. Trata-se de um grave engano, pois a Teoria é a consubstanciação de décadas de formulações teóricas do autor, associadas à sua experiência à frente do ICR. Ademais, como exposto no próprio livro, a Teoria é também resultante de escritos anteriores e das aulas ministradas por Brandi; aulas destinadas à formação de um corpo profissional capacitado do ponto de vista teórico-crítico e operacional. Suas formulações teóricas não estavam, de modo algum, desvinculadas da prática do Instituto; antes, regiam-na e eram, por isso, continuamente verificadas e confrontadas com a realidade. E continuam a sê-lo, uma vez que as proposições de Brandi seguem sendo referência incontornável na formação dos alunos do Instituto e nas restaurações ali feitas.

Por se fundamentar na relação dialética entre as "instâncias" estéticas e históricas da obra (ou conjunto de obras), suas proposições exigem esforço 
interpretativo caso a caso, e a intervenção não pode ser enquadrada, a priori, em uma determinada categoria fixa como acontecera anteriormente, em especial com as formulações de Gustavo Giovannoni.

Mas o fato de cada restauração constituir um caso a ser analisado de modo singular - em razão das características particulares de cada obra e de seu individual transcorrer na história - e não obedecer a colocações dogmáticas, não significa que a intervenção seja arbitrária. Como já notara Frodl, a teoria tende a uma generalização, enquanto os monumentos são sempre "indivíduos". Por que então uma teoria? Justamente por refletir sobre o método para se chegar ao conhecimento. Deve-se notar que nesse campo é absolutamente indesejável trabalhar com "modelos" pré-concebidos e com regras fixas, mas se deve trabalhar através de sólida metodologia que respeite a complexa estrutura e estratificações históricas da obra. Dada a responsabilidade envolvida - social e perante a história e as ciências, no presente e no futuro - é necessário resolver o problema de modo que a idéia subjetiva se torne acessível a um juízo mais objetivo e controlável. Essa objetividade só pode ser alcançada através da reflexão teórica ${ }^{19}$.

Por isso a restauração deve seguir princípios gerais (não admitindo aplicações mecânicas de fórmulas nem de "regras" fixas) através de metodologia e conceitos consistentes, ancorados na história e na filosofia. A "ancoragem" nesses campos disciplinares é essencial para aqueles que atuam na preservação de bens culturais, pois possibilita que se supere atitudes ditadas unicamente por predileções individuais, que qualquer ser pensante possui, e que se aja de acordo com uma deontologia profissional, alicerçada em uma visão histórica, associada a estudos multidisciplinares, justamente para se minimizar o risco de atitudes individualistas e de interpretações parciais. A restauração deve, ainda, ter em vista três princípios fundamentais, sempre pensados de forma concomitante:

- Distinguibilidade: pois a restauração (que é vinculada às ciências históricas) não propõe o tempo como reversível e não pode induzir o observador ao engano de confundir a intervenção ou eventuais acréscimos com o que existia anteriormente, além de dever documentar a si própria.

- Reversibilidade: pois a restauração não deve impedir, tem, antes, de facilitar qualquer intervenção futura; portanto, não pode alterar a obra em sua substância, devendo-se inserir com propriedade e de modo respeitoso em relação ao preexistente. 
- Mínima intervenção: pois a restauração não pode desnaturar o documento histórico nem a obra como imagem figurada.

Existem também finalidades comuns à preservação, pois, como exposto na Carta de Veneza, a restauração baseia-se no respeito pela obra tendo por objetivo "conservar e revelar os valores estéticos e históricos do monumento e fundamentase no respeito pelo material original e pelos documentos autênticos" ${ }^{20}$. Os caminhos para se atingir os objetivos da restauração não são unívocos, verificando-se atualmente variadas tendências. Convém lembrar que muito daquilo que se faz em monumentos históricos (na verdade contra), hoje em dia, não leva minimamente em consideração os objetivos acima expostos e, na prática, acaba-se por desrespeitar aquilo que se diz querer preservar.

Voltando às tendências atuais que possuem de fato caráter cultural e procuram seguir os objetivos da preservação, deve-se enfatizar que são fundamentadas em pelo menos dois séculos acumulados de experiências e de reflexões sobre o tema. Entre elas, pode-se citar aquela que Carbonara denomina e interpreta como "críticoconservativa e criativa" ${ }^{21}$ e Miarelli Mariani chama de "posição central"22, à qual são vinculados ambos os autores, alicerçada na teoria brandiana e na releitura de aspectos do chamado restauro crítico. Nessa vertente a restauração assume uma posição conservativa, de forma prudente, que não significa de modo algum congelamento, e não prescinde, antes, propõe, quando necessário, o uso de recursos criativos (utilizados, porém, com respeito pela obra e não em detrimento dela), necessários para tratar várias questões que podem estar, e em geral estão, envolvidas na restauração, tais como a remoção de adições e reintegração de lacunas. É postura fundamentada no juízo histórico-crítico, na análise da relação dialética entre as instâncias estéticas e históricas de cada obra, caso a caso, que exclui, na prática, qualquer tipo de interpretação mecânica de relação causa-efeito. É postura, pois, que devota grande atenção aos valores documentais e formais da obra como imagem figurada. Deve-se levar em conta que com a ampliação daquilo que se passou a considerar monumento histórico, existe um grande número de obras que possuem valor prevalentemente documental, a ser respeitado escrupulosamente.

Outra vertente é a chamada "pura conservação" ou "conservação integral", que privilegia a instância histórica e encara como ações opostas e inconciliáveis, em seu âmago, a restauração e a conservação, retomando uma discussão que tem suas 
raízes no século XIX e perpassa pelas formulações de autores tais como Didron, Ruskin, Morris, Boito e Riegl. Existem contribuições de grande interesse oferecidas por autores vinculados a essa vertente, a exemplo dos escritos de Marco DezziBardeschi, Amedeo Bellini, Anna Lucia Maramotti e, ainda, de B. Paolo Torsello que se aproxima dessa linha de pensamento, que fornecem importantes elementos para a reflexão sobre uma realidade sempre mais variada e abrangente ${ }^{23}$.

Nessa vertente, como analisada por Carbonara e Miarelli Mariani, não se trabalha contemporaneamente como relação dialética a articulação das instâncias estética e histórica, que em certos casos poderia resultar em ações tais como a remoção de adições ou tratamento de lacunas com vistas à reintegração da imagem, algo que a corrente da conservação integral repudia. É importante salientar que para essa vertente a conservação não é mero apêndice do restauro, nem um grau de intervenção, como exposto, por exemplo, na Carta de Veneza. É coisa totalmente distinta, uma postura em que não existe uma distinção entre as instâncias histórica e estética, que são fato único e indissolúvel, intimamente relacionadas, entrelaçadas; ou seja, a conformação decorre também da passagem do objeto pelo tempo e a instância histórica deve ser respeitada de modo absoluto. Desse modo, a matéria é preservada tal qual chegou a nossos dias, não se atuando através de juízo de valor. Retomam-se, assim, proposições enunciadas por Riegl, que mostrava não fazer sentido separar, em categorias distintas, o monumento histórico do monumento artístico, pois toda obra de arte é um fato histórico e todo documento histórico mesmo um pedaço de papel rasgado portando uma nota breve e sem importância possui uma conformação ${ }^{24}$. Para o restauro crítico, as instâncias estética e histórica são analisadas, do ponto de vista metodológico, interagindo através de dialética, mas de modo algum possuem autonomia absoluta, não são destacáveis, são faces de um mesmo bem multifacetado, são dois aspectos coexistentes e paritários ${ }^{25}$. Convém ainda enfatizar que também na conservação integral, como não poderia deixar de ser, a manutenção é essencial, assim como é primordial eliminar as causas de degradação e remover patologias e sujeiras.

A conservação integral parte, como explicita Carbonara, de correntes historiográficas que questionam a existência de testemunhos relevantes, e outros nem tanto, para a história. Para responder de modo afirmativo, deveria ser possível um conhecimento total, algo que a reflexão histórica nega, enfatizando que juízos historiográficos são sempre relativos e o conhecimento do passado é limitado. Um 
juízo histórico-crítico "infalível" não existe, sendo uma invenção positivista do século XIX e, portanto, não se deveria julgar, devendo-se privilegiar a instância histórica, ou seja, preservar o documento em sua integridade. Na vertente crítico-conservativa, o juízo histórico-crítico tem de ser baseado na história da arte e na estética, justamente para que seja um juízo, e não uma opinião e nem um ato arbitrário, tendo-se plena consciência de que é ação do presente - e, portanto, não é atemporalmente válido - e possui pertinência relativa. Segundo a conservação integral, deve-se reconhecer que as várias estratificações da obra, que devem ser rigorosamente respeitadas, possam apresentar descontinuidades, admitindo-se uma configuração final da obra com conflitos e, mesmo, contradições. O projeto de transformação de uma obra arquitetônica (para um novo ou mesmo uso) em si, não faz parte do processo de conservação, propondo-se a separação do momento da conservação propriamente dita, que busca perpetuar integralmente os aspectos materiais da obra, daquele da inovação, que se segue à conservação e se assemelha ao projeto do "novo". Nesse sentido, difere da corrente críticoconservativa que trabalha de modo articulado com o momento conservativo e de inovação. O momento da criação, na conservação integral, comporta-se como adição à obra, excluindo, assim como na vertente crítico-conservativa, qualquer possibilidade de imitação ou mimetismo, conferindo ainda imenso espaço para a liberdade expressiva. Apesar de se comportar como projeto do novo, cabe lembrar as palavras de Marco Dezzi Bardeschi a esse respeito: "um projeto do novo compatível mas não mimético, isto é respeitoso, dialeticamente consciente e, ao mesmo tempo, declaradamente legível e autônomo"26.

No pólo oposto, encontra-se a chamada "manutenção-repristinação" ou "hipermanutenção" que propõe o tratamento da obra através de manutenções ou integrações, ordinárias e extraordinárias, retomando formas e técnicas do passado. Como nota Torsello, esta última postura parte de um pragmatismo de base, parte da própria obra e baseia-se numa lógica indutiva, enquanto a teoria brandiana, parte, ao contrário, de uma lógica dedutiva fundamentada em axiomas éticos e científicos $^{27}$, e depois se volta para a análise pormenorizada da obra em seus aspectos materiais, formais e históricos. Tanto a "posição central" quanto a pura conservação preconizam e valorizam a diversidade, enquanto na "manutençãorepristinação" existe um pragmatismo de base com tendência maior a se trabalhar por analogia $\mathrm{O}$ mais conhecido dos defensores dessa vertente entre nós é Paolo 
Marconi $^{28}$.

Neste ponto, é importante salientar que essas vertentes, que têm representantes nos vários países, apesar de por vezes operarem de maneira distinta, preconizam um respeito absoluto pelo valor documental da obra, mesmo na pluralidade de suas formulações e dos diversos modos de colocá-las em prática. As formulações teóricas vinculadas à conservação e restauração - que entendem o campo como essencialmente cultural - permitem que pelo menos se circunscreva e se defina o campo de ação de maneira adequada e fundamentada, separando-o daquilo que exorbita completamente dos objetivos da preservação; pois uma coisa é possuir uma pertinência relativa; outra, é ser de todo impertinente ao campo.

A preservação possui pertinência relativa, não apenas em relação aos parâmetros culturais (e sócio-econômico-políticos) de cada época, mas também àqueles de épocas anteriores e do porvir. Não é possível prever quais serão os critérios empregados no futuro que, com toda probabilidade, serão diversos dos atuais. Isso repercute inclusive na tarefa basilar que conjuga a história da arte, arquitetura e restauração, o inventário. Mas a questão da conservação de monumentos históricos deve ser discutida e enfrentada dentro da realidade e com os instrumentos de cada época, e o fato de, no futuro, as posturas serem diversas não nos exime da responsabilidade pela preservação dos bens culturais e nem da necessidade de agirmos em relação ao legado de outras épocas. Como exposto na Carta de Veneza, na abertura:

Portadoras de mensagem espiritual do passado, as obras monumentais de cada povo perduram no presente como o testemunho vivo de suas tradições seculares. A humanidade, cada vez mais consciente da unidade dos valores humanos, as considera um patrimônio comum e, perante as gerações futuras, se reconhece solidariamente responsável por preservá-las, impondo a si mesma o dever de transmiti-las na plenitude de sua autenticidade.

Brandi expusera que o fato de se reconhecer a obra de arte como tal, impõe a quem reconhece o imperativo moral da sua conservação ${ }^{29}$. E também por isso, é imperioso que a análise que guia a intervenção seja muito bem fundamentada, pois somos responsáveis pelos nossos atos perante o presente e perante as gerações futuras.

No Brasil, nessas últimas décadas temos visto crescentes esforços no campo, com a produção de numerosos escritos de grande valia ${ }^{30}$. Escritos voltados, em sua 
maioria, para a análise das políticas públicas de preservação, releituras críticas da atuação dos órgãos de preservação etc. No entanto, o debate no país sobre critérios e princípios teóricos que deveriam reger a restauração existe, mas permanece muito limitado. Apesar da vasta produção intelectual de profissionais ligados à área (atuante não apenas nos órgãos de preservação, mas também nas universidades, em instituições culturais, em sociedades civis etc), os princípios de preservação - ou seja, os fundamentos teóricos que deveriam reger a atuação prática em bens culturais - nunca foram incorporados em nossa legislação. Existem algumas indicações nas leis de tombamento, mas que, na verdade, são lacônicas sobre esse problema.

Principalmente a partir dos anos 1970, após a releitura crítica das experiências realizadas pelo SPHAN em sua fase pioneira - com várias intervenções que privilegiaram uma dada leitura da história da arquitetura brasileira, que não consideravam como válidas as diversas fases por que passou um monumento histórico, e o desprezo generalizado por grande parte da produção arquitetônica do século $X I X$ e início do século $X X$-, houve certa convergência para os princípios amadurecidos nas posturas conceituais, em especial italianas, do século $X X$, incorporadas na Carta de Veneza, de 1964, documento base do ICOMOS / UNESCO, da qual o Brasil é signatário.

Mas ainda inexiste uma discussão teórica aprofundada voltada à nossa realidade, que visasse a formular uma carta de princípios nacional, com repercussão na legislação, como acontece em outros países, que deveria inquirir e integrar os preceitos da Carta de Veneza e outras cartas e recomendações internacionais. O intuito seria tornar esses preceitos adequados e atuais em nosso meio, oferecendo um quadro mais vasto de referência, pois se verifica uma ampliação crescente e legítima daquilo que é considerado bem de interesse cultural a ser preservado, estendendo-se a um número cada vez maior, a tipos cada vez mais variados e a um passado cada vez mais próximo.

O constante alargamento daquilo que é considerado bem cultural resultou em renovado problema quantitativo e qualitativo, colocando uma série de novas questões, tanto teóricas, quanto técnicas, práticas e éticas, que devem ser analisadas para enfrentá-las. Esses fatores acabaram, no entanto, por levar a um afastamento do debate de seu lugar de direito, que é o foro cultural, que de início motivou a preservação, para um âmbito diverso, havendo uma interferência 
justificável, mas que está assumindo proporções desequilibradas, de pressões econômicas, utilitárias e políticas, que não podem ser desconsideradas na preservação, mas tampouco podem ser as únicas e preponderantes.

Distintas formas de perceber os monumentos históricos devem coexistir. É necessário ter em mente, porém, que o movente, aquilo que de início motivou a preservação não foi seu valor monetário, nem seu possível aproveitamento para um uso qualquer. A preservação foi motivada pelo fato de nesses bens ser reconhecido um significado cultural - seu valor estético (ou, mesmo não sendo "obras de arte", obras que possuem uma configuração) histórico, memorial e simbólico - tornando-os dignos de medidas para ser tutelados para as próximas gerações. Portanto, deveriam ser essas as razões prevalentes para guiar as decisões. Com certeza aparecerão conflitos, mas isso não significa que uma solução pertinente seja impossível.

Não se trata de conservar tudo, nem, tampouco, de demolir ou transformar indistintamente tudo. Isso denotaria negligência, deixando-se de assumir a responsabilidade por ações fundamentadas. Deve-se reconhecer que todas as épocas, que as várias fases da produção humana, possuem interesse e são merecedoras de estudo e tutela, mas isso não se traduz automaticamente em preservar todo e qualquer testemunho, material ou não, legado pelo passado. Isso resulta em certas escolhas, voluntárias ou involuntárias. No que se refere à uma ação propositiva de escolha, cabe uma ressalva da maior importância: não se trata de opinião pessoal, de gosto ou capricho; deve-se tratar de estudo consciencioso, formulado por equipes multidisciplinares, fundamentado na antropologia, na sociologia, na história em geral, e em especial na história da arte e da arquitetura, na estética, nas ciências de modo amplo, e jamais, de modo algum, de ato arbitrário.

É fato incontestável, em se tratando de intervenções em bens culturais que qualquer ação, por mais restrita que seja, até mesmo obras de manutenção ou uma limpeza, controlada e limitada, gera mudanças na leitura da obra, implica modificações. Ou, como colocou Leonardo Benevolo, a conservação não pode significar a ausência de uma intervenção, pois as coisas deixadas à própria sorte se modificam de qualquer modo, e nem denotar o bloqueio de uma ação, mas quer dizer intervir de uma certa maneira e, por conseqüência, modificar a realidade ${ }^{31}$. Qualquer intervenção numa obra, pois, implica, que em geral, resultam em algum tipo de destruição que deve ser mínima e controlada e deve ser judiciosamente 
fundamentada ${ }^{32}$. Deveria, portanto, ser a preservação a condicionar as eventuais ações "não-conservativas" e não o contrário. Apesar de qualquer intervenção implicar mudanças, isso não deve significar cancelar fatos históricos de interesse para, naquele espaço, sobrescrever uma nova história, por melhor que seja essa "nova história". Na arquitetura, em que em geral, a "mínima intervenção" assume um vulto maior, e em que muitas vezes são necessárias adições (mesmo que de natureza essencialmente técnica como uma nova rede hidráulica ou instalações elétricas) a ação contemporânea deve se colocar como um novo estrato, uma aposição, uma justaposição, uma integração e jamais como eliminação ou substituição de documentos históricos para forçar uma nova realidade totalmente diversa daquilo que lá existe.

Camillo Boito já alertava, há mais de um século, que para "bem restaurar é necessário amar e entender o monumento" ${ }^{33}$. A preservação deve ser conseqüência de esforços multidisciplinares que envolvem acurada pesquisa histórico-documental, iconográfica e bibliográfica, sensíveis estudos antropológicos e sociológicos, pormenorizado levantamento métrico-arquitetônico e fotográfico do(s) edifício(s) (ou empregar as modernas técnicas de laser scan em três dimensões), exame de suas técnicas construtivas e dos materiais, de sua estrutura, de suas patologias, e análise tipológica e formal. Fatores esses que levam ao entendimento das várias fases por que passou a obra no decorrer do tempo e de sua configuração e problemas atuais. A restauração e a conservação devem calcar-se em muitos campos disciplinares distintos (cada um com a devida autonomia, que é algo diverso de isolamento), tais como engenharia, química, física, biologia, arquitetura, e depende sobremaneira da história, podendo, por sua vez, através desses estudos conscienciosos dos bens, fornecer importantes dados para esclarecimentos historiográficos. Envolvem, pois, vários campos disciplinares, que devem trabalhar de forma integrada. $O$ conhecimento aprofundado deveria conduzir à compreensão e, por conseguinte, ao respeito pela(s) obra(s), requisito essencial quando se trata de bens culturais, que leva a posturas verdadeiramente conservativas. Pois intervir num bem de interesse cultural, que é um documento histórico e possui papel memorial é ato de extrema responsabilidade, pois se trata, sempre, de documentos únicos e não reproduzíveis. Essa percepção deveria levar à conscientização, pelo fato de qualquer intervenção, de modo forçoso, alterar o bem, de que uma mudança não controlada leva a perdas irreparáveis, lembrando-se que os organismos históricos são muito delicados. 
É preciso, portanto, projetar considerando ao mesmo tempo os condicionantes de partido históricos, formais e materiais, pois a restauração deve preservar e facilitar a leitura dos aspectos estéticos e históricos do monumento, sem prejudicar o seu valor como documento e sem eliminar de forma indistinta as marcas da passagem do tempo na obra ${ }^{34}$.

A preservação, como entendida hoje, tem a característica bastante peculiar, em relação a épocas passadas, de voltar seus interesses para a tutela de um grande número de bens que adquiriram conotação cultural, pertencentes a todas as fases da produção humana. Tem-se (em teoria), maturidade para reconhecer o interesse dos vários momentos históricos, independente da maior ou menor afinidade ou apreciação pessoal ou de uma dada sociedade por esses momentos. É um contrasenso desprezar essa conquista contemporânea e voltar a valores oitocentistas, ou anteriores, de dirigir o cuidado, no trato e na tutela, apenas aos testemunhos daqueles períodos que são mais apreciados por uma dada cultura ou apenas por um setor da sociedade. Os profissionais ligados à preservação deveriam, portanto, possuir visão "histórica" e sobretudo conservadores, restauradores, arquitetos, engenheiros, historiadores etc. que participam de estudos, inventários e intervenções em bens culturais, devem ter sólida formação e consciência da responsabilidade envolvida. Claro está, como mencionado, que qualquer um desses profissionais tem predileções individuais, dado que, como expôs Scarrocchia, não é um "idiota útil", mas deve superá-las na prática em função de uma deontologia apropriada $^{35}$ para não recair no arbítrio. Daí a importância de estudos multidisciplinares sólidos, extensos, que devem levar o tempo condizente e necessário para se elaborar análises consistentes e historicamente fundamentadas.

$O$ fato é que os instrumentos de reflexão oferecidos pelas vertentes teóricas da conservação e da restauração permitem que se atue em monumentos históricos de modo adequado e responsável, sem deformar e deturpar o documento, a memória, os bens legados pelo passado, que fazem parte integrante de nosso presente. Não se trata de imobilismo, congelamento, muito menos de necrolatria. A preservação é um legítimo ato de respeito pelo passado, que, alicerçado no reconhecimento da obra de arte e de seu transformar no decorrer do tempo, insere-se no tempo presente. Deve sempre ser ato de reinterpretação do presente, em que se propõe, de maneira socialmente e culturalmente responsável, uma renovada forma de se relacionar com um monumento histórico, voltado para sua transmissão para as 
próximas gerações da melhor maneira possível e, portanto, uma ação que mantém sempre o futuro no horizonte de suas reflexões.

Monumentos históricos - é necessário repetir à exaustão - são únicos e não reproduzíveis e devem portar consigo para o futuro seus elementos caracterizadores e as marcas de sua translação no tempo; todo cuidado é pouco, pois esses monumentos, que são documentos históricos e instrumentos, suportes materiais, da memória individual e coletiva permitem infinitas possibilidades de atualização e interpretação ao longo do tempo, por um grupo social ou por uma consciência individual, oferecendo, sempre, renovadas leituras, que serão cada vez percebidas e apreendidas de modo diverso, e podem, continuamente, de diferentes formas, por esta e pelas gerações do porvir, oferecer instrumentos importantes de reflexão para uma adaptação harmoniosa à realidade.

No entanto, a verdade é que atualmente o papel dos monumentos para nossa sociedade não é nítido e não temos definidos os critérios para sua preservação, e isso transparece na falta de clareza conceitual de muitas de nossas ações em relação aos bens culturais. Cabe repensar a questão, voltar às suas raízes, e tentar voltar a entender por que preservar. Essa pergunta deveria levar ao "o que" preservar e, por conseguinte, ao como fazê-lo. Se colocarmos essas questões, dando-Ihes a devida importância, procurando respondê-las do modo mais amplo, fundamentado e socialmente responsável possível, talvez então, apesar das discordâncias e diferenças que existem e sempre existirão (e devem existir), possamos estabelecer as bases para um verdadeiro e frutífero diálogo.

Essas questões, pelas suas implicações para a sociedade como um todo, não são nem retóricas nem supérfluas. Um país que promoveu recentemente discussões sobre o patrimônio imaterial ${ }^{36}$ retomando as pioneiras e sensíveis propostas de Mário de Andrade, é porque acredita no conhecimento, oferecido também pelos instrumentos da memória, materiais ou imateriais, como modo de adaptação às exigências da vida e, nesse sentido, deveria promover renovados esforços para aprofundar a discussão sobre critérios de preservação.

John Ruskin, em meados do século XIX, foi um dos primeiros a enfatizar, como bem nota Petrella, a relação entre ambiente natural e patrimônio histórico ${ }^{37}$, que são bens comuns, por não serem "apropriáveis" unicamente por um individuo, mesmo sendo de propriedade privada, e que, desse modo, podem trazer benefícios a toda 
sociedade. Existem vários pontos em comum entre a preservação de bens culturais e a de áreas naturais, sendo fundamental, em ambas, assegurar a diversidade.

Assegurar a biodiversidade é uma questão premente. Grande parte da população depende diretamente da natureza para a alimentação, para a obtenção de remédios, para o vestuário, para a construção de casas etc. Somente assegurando um uso responsável e a preservação da natureza em escala mais ampla será possível explorar toda uma série de benesses ainda desconhecidas, que podem ter incidência sobre a vida do ser humano. O homem destruindo o ambiente natural ameaça sua própria sobrevivência, com repercussão direta sobre o clima, o ar, a água de que necessita para viver, os alimentos e remédios.

O homem destruindo, degradando ou desnaturando os monumentos históricos apaga suas raízes, deturpa a própria memória, deforma as lições deixadas pelo passado, condenando-se a nunca ir além do empirismo. Uma sociedade deturpando sua cultura e sua memória, destrói os instrumentos que são seus próprios meios de expressão como seres vivos, com incidências sobre a memória individual e coletiva, podendo gerar problemas para a identidade como comunidades, povo ou nação ${ }^{38}$.

A imprudência em relação aos monumentos históricos e a seus aspectos documentais, resultam na perda de um valor fundamental, que é diversidade, a multiplicidade. Perda de multiplicidade que nega um preceito que deveria estar presente na vida em geral, que é a tolerância. Preservar apenas aquilo que parece proveitoso a alguns em um dado momento, é a subversão desse preceito. As pessoas sendo tolerantes, como nos ensina Georg Mörsch, condenando veementemente o fachadismo, "poupam e cuidam também dos objetos que naquele momento não são diretamente úteis e interessantes e garantem a possibilidade de escolha para um futuro imprevisível e desse modo, também um pedaço de liberdade" ${ }^{39}$.

Ou seja, negligência, abandono, destruições, transformações imponderadas de monumentos e sítios históricos (elementos de rememoração, instrumentos da memória), afetam a integridade material e a autenticidade, implicam intolerância, que leva ao aniquilamento da multiplicidade, que resulta num instrumental deficiente para compreender e se adaptar à própria realidade atual e futura - e por conseguinte, impõe limitações à própria possibilidade de liberdade -, podendo gerar perturbações tanto para o indivíduo quanto para a coletividade. Por isso toda a importância dada à preservação dos monumentos-documentos da forma mais ampla possível. 
É relevante enfatizar que o estudo do monumento, conhecê-lo de forma aprofundada, leva ao entendimento, ao respeito e a uma boa restauração como colocara Boito. Mas é ainda mais imprescindível recordar que não se trata apenas de conhecer para bem conservar, mas também, e talvez sobretudo, como mostram os ensinamentos de Riegl e como professara Paul Clemen $^{40}$, "conservar para conhecer". ${ }^{41}$

\section{Notas}

${ }^{1}$ Cf. por exemplo: LÉON, Paul. Les monuments historiques, conservation, restauration. Paris: Renouard, 1917; La vie des monuments français. Paris: Picard, 1951; MARAMOTTI, Anna Lucia. Rapporto fra le Teorie del restauro critico e le estetiche neo-idealiste. Restauro, Nápoles, n. 80, p. 36-64, 1985.

${ }^{2}$ Para a análise das transformações da noção de restauro ao longo do tempo até os debates contemporâneos, ver: CARBONARA, Giovanni. Avvicinamento al restauro. Napoli: Liguori, 1997; CHOAY, Françoise. A alegoria do patrimônio. São Paulo: Unesp, 2001; JOKILEHTO, Jukka. A history of architectural conservation. Oxford, Butterworth, 1999.

3 Para uma análise pormenorizada do papel de Riegl para a tutela dos monumentos, em que são também apresentadas e analisadas formulações de variados autores, ver: SCARROCCHIA, Sandro. Alois Riegl: Teoria e prassi della conservazione dei monumenti. Bologna, Accademia Clementina di Bologna, 1995.

${ }^{4}$ Ver a contribuição de autores tais como Margaret Olin, Wolfgang Kemp e Jörg Oberhaidacher e a análise de Scarrocchia, op. cit., p. 29-35. Ver: OLIN, Margaret. Forms of Respect: Alois Riegl's Concept of Attentiveness. The Art Bulletin, v. 71, n. 2, p. 285-299, 1989; KEMP, Wolfgang. Alois Riegl. In: DILLY, H. (org.). Altmeister moderner Kunstgeschichte. Berlin, 1990, p. 37-60; OBERHAIDACHER, Jörg. Riegls Idee. Wiener Jahrbuch für Kunstgeschichte, v. 28, p. 199-218, 1985.

${ }^{5}$ SCARROCCHIA. Op. cit., em especial p. 91-110. Ver sobretudo o texto de Riegl, Progetto di un'organizzazione legislativa della conservazione in Austria, que faz parte da antologia de textos do autor organizada por Scarrocchia (p. 171-236).

${ }^{6}$ Riegl esquematizou-os em valores de "rememoração" e valores de "contemporaneidade", subdividindo-os por sua vez em várias classes. Os valores de rememoração eram divididos em valor de "antigüidade" ou valor "de antigo", valor "histórico" e valor de "rememoração intencional". O "valor de antigüidade", para sua eficácia, depende da preservação escrupulosa das várias estratificações da obra e inclusive das marcas da passagem do tempo, apreciando-se as formas de dissolução. Já ao valor histórico, interessa deter toda degradação a partir do momento em que se realiza a intervenção, perenizando a imagem e o documento que se recebeu no presente. Ao "valor de rememoração intencional" interessa a perenidade do estado original, atendo-se ao ato em si da edificação do monumento. No que se refere aos valores de "contemporaneidade", Riegl afirma que a maior parte dos monumentos pode responder às expectativas contemporâneas dos sentidos ou do espírito; desse modo, são 
subdivididos em "valor de uso" e "valor artístico", e este último se reparte em "valor como novidade" e "valor artístico relativo".

${ }^{7}$ SCARROCCHIA. Op. cit., especialmente p. 55-73.

${ }^{8}$ Ver as considerações de Riegl em a Lei de Tutela (In: SCARROCCHIA. Op. cit., em especial p. 209-210), mostrando o caráter mais inclusivo do valor de antigüidade, baseado na "solidariedade com todo o mundo". Ver ainda, de Riegl, As disposições para a aplicação da lei (In: SCARROCCHIA. Op. cit., p. 222-236). Cita-se da p. 224.

${ }^{9}$ RIEGL, Alois. Le culte moderne des monuments, son essence et sa genèse. Paris, Seuil, 1984. Ver a esse respeito as pertinentes análises feitas por Françoise Choay no ensaio introdutório ao volume, "A propos de culte et de monuments", p. 7-19.

${ }^{10}$ No que se refere às definições de restauração e a uma análise do restauro crítico, ver CARBONARA, Op. cit., p. 271-390. Na p. 285: "[O restauro crítico] parte da afirmação de que toda intervenção constitui um caso em si, não possível de classificar em categorias (como aquelas meticulosamente precisadas pelos teóricos do chamado restauro 'científico': completamento, liberação, inovação, recomposição etc.), nem responde a regras prefixadas ou a dogmas de qualquer tipo, mas deve ser reinventado com originalidade, de vez em vez, caso a caso, em seus critérios e métodos. Será a própria obra, indagada atentamente com sensibilidade histórico-crítica e com competência técnica, a sugerir ao restaurador a via mais correta a ser empreendida".

${ }^{11}$ BRANDI, Cesare. Teoria da Restauração. Cotia: Ateliê, 2004, p. 30.

12 Para uma análise da fenomenologia no pensamento brandiano e para referências complementares sobre o tema, ver: PHILIPPOT, Paul. The phenomenology of artistic creation according to Cesare Brandi. In: BRANDI, Cesare. Theory of Restoration. Firenze: Nardini, 2005, p. 27-41. Para o pensamento de Brandi sobre estética, ver também: CARBONI, Massimo. Cesare Brandi. Teoria e esperienza dell'arte. Roma: Editori Riuniti, 1992.

${ }^{13}$ BRANDI, Cesare. Celso della poesia. Torino: Einaudi, 1956. Para um aprofundamento das teorias estéticas de Brandi, é necessário retomar seus vários escritos sobre o tema, tais como, além do supracitado: BRANDI, Cesare. Arcadio o della Scultura. Eliante o della Architettura. Torino: Einaudi, 1956; Carmine o della Pittura. Firenze: Vallecchi, 1947; Il Restauro. Teoria e Pratica. Roma: Editori Riuniti, 1994; Segno e Immagine. Palermo: Estetica, 1996; Struttura e Architettura. Torino: Einaudi, 1975; Teoria Generale della Critica. Torino: Einaudi, 1977.

${ }^{14}$ ANTINUCCI, Paolo. Introduzione. In: BRANDI, Cesare. In Situ. Viterbo, Sette Città, 1996, p. 7-33, em especial p. 18-19.

${ }^{15}$ BRANDI, Teoria ..., op. cit., p. 27. Agradeço Giuseppe Basile - que foi aluno de Brandi e é atualmente diretor do serviço de intervenções em bens históricos e artísticos do ICR - por várias sugestões bibliográficas e pela paciente e pormenorizada discussão de variados aspectos da teoria brandiana. 
${ }^{16}$ O processo histórico crítico tem por objetivo afastar as ações da esfera do arbitrário. Outra falsa crença em relação ao pensamento de Brandi, é questionar se a Teoria seria aplicável a obras pelas quais ele não teria maior apreço, como, por exemplo, a arquitetura do século XIX. Esse tipo de raciocínio se constitui em um sofisma. Vincular o restauro ao processo histórico-crítico é afastá-lo do empirismo e da arbitrariedade para ancorá-lo às ciências, impondo à ação do restaurador uma sólida deontologia profissional, independente de sua "opinião" pessoal sobre uma dada obra. Se a obra foi reconhecida como bem cultural, sendo tutelada por lei (ou mesmo não o sendo), ela deve ser restaurada com todo o rigor. Ademais, Brandi jamais se colocou como senhor onipotente e onisciente para decidir sobre tudo aquilo que é ou deixa de ser de interesse para a preservação, de modo absoluto. Outro problema é imputar uma opinião do autor sobre obras a respeito das quais ele não se manifestou (e nem conheceu); engano é ainda considerar que ele desprezaria, por exemplo, toda e qualquer obra do século XIX. Giuseppe Basile informa que, ao contrário, Brandi tinha espírito bastante aberto para as várias formas de manifestação artística e era extremamente sensível ao significado de uma dada obra para o local em que se encontra, de qualquer época que fosse. Ademais, suas restrições eram em relação a certa parte da produção artística do XIX, e não a toda e qualquer obra produzida no período.

${ }^{17}$ BRANDI, Teoria ..., op. cit., p. 100-101.

${ }^{18}$ BRANDI, Cesare. L'Institut Central pour la Restauration d'œuvres d'art a Rome. Gazette des Beaux-Arts, Paris v. 43, p. 42-52, 1954. Nesse artigo, Brandi discorre sobre a organização e os trabalhos realizados pelo instituto. Cita-se da p. 42-44.

${ }^{19}$ FRODL, Walter. Concetti, valori di monumento e il loro influsso sul restauro. In: SCARROCCHIA, op. cit., p. 401-412. Ver, em especial, p. 401-402.

${ }^{20}$ Carta de Veneza (1964). Revista do Patrimônio Histórico e Artístico Nacional, Rio de Janeiro, n. 22, art. 9, p. 106, 1987.

${ }^{21}$ No que se refere às propostas teóricas atuais e referências bibliográficas complementares, v. CARBONARA, Avvicinamento, op. cit., em especial p. 393-439.

22 MIARELLI MARIANI, Gaetano. I restauri di Pierre Prunet: un pretesto per parlare di architettura. Palladio, Roma, n. 27, p. 65-92, 2000. Sobre as variadas vertentes, ver p. 65-67. Agradeço Simona Salvo pela referência e pela cópia do texto. Miarelli Mariani oferece sua interpretação das várias vertentes atuais, e enfatiza a necessidade de se superar o péssimo costume de aumentar, nas convicções dos outros, aquilo que as distingue da nossa, em vez de ver traços em comum. Esse é um meio de abrir diálogo, de discutir em profundidade e de saber conviver em momento de pluralismo, procurando superar o isolamento de posições fechadas e individuais e participar de forma aberta numa atividade ampla e complexa como a arquitetônica.

${ }^{23}$ Ver, por exemplo: MARAMOTTI, Anna Lucia. Passato, Memoria, Futuro. La conservazione dell'architettura. Milano: Guerini, 1996. BELLINI, Amedeo (org.). Tecniche della conservazione. Milano: Franco Angeli, 2003.

${ }^{24}$ RIEGL, Alois. Le culte..., op. cit., p. 38. 
${ }^{25}$ Deve-se recordar a dúplice polaridade estética e histórica da definição de Brandi e que a ação deve ser feita "sem cometer um falso artístico ou um falso histórico, e sem cancelar nenhum traço da passagem da obra de arte no tempo."

${ }^{26}$ BARDESCHI, Marco Dezzi. Restauro: due punti e da capo. Milano: FrancoAngeli, 2004, p. 487.

${ }^{27}$ TORSELLO, B. Paolo. La Materia del Restauro. Venezia: Marsilio, 1988, p.24.

${ }^{28}$ Ver, por exemplo: MARCONI, Paolo. Materia e Significato. Roma: Laterza, 1999; Dal Piccolo al Grande Restauro. Venezia, Marsilio, 1988; . Il Restauro e l'Architetto. Venezia: Marsilio, 1993.

${ }^{29}$ BRANDI. Teoria..., op. cit., p. 31: "Na verdade, apesar de o reconhecimento dar-se sempre na consciência singular, naquele mesmo momento pertence à consciência universal, e o indivíduo que frui daquela revelação imediata, impõe a si próprio o imperativo categórico como o imperativo moral, da conservação."

${ }^{30}$ Destacam-se textos de vários autores cuja produção intelectual também se volta à preservação de bens culturais, tais como Ulpiano Bezerra de Meneses, Benedito Lima de Toledo, Carlos Lemos, José Liberal de Castro, Mário Mendonça, Nestor Goulart Reis Filho, Paulo Ormindo de Azevedo, entre outros. Também nos últimos anos, a discussão sobre a formação dos órgãos de preservação e sua atuação ao longo do tempo têm aumentado, dando origem a vários escritos do maior interesse, tais como: ANDRADE, Antonio Luiz Dias de. Um Estado Completo que pode jamais ter existido. 1993. Tese (Doutorado) FAU-USP; ARANTES, Antonio Augusto (org.). Produzindo o passado: Estratégias de Construção do Patrimônio Cultural. São Paulo::Brasiliense, 1984; CASTRO, Sonia R. O Estado na Preservação de Bens Culturais: o Tombamento. Rio de Janeiro: Renovar, 1991; FONSECA, Maria Cecília Londres. O Patrimônio em Processo: trajetória da política federal de preservação no Brasil. Rio de Janeiro: UFRJ/MinC/IPHAN, 1997; PESSOA, José (org.). Lúcio Costa: Documentos de Trabalho. Rio de Janeiro: IPHAN, 1999; RODRIGUES, Marly. Imagens do Passado: a instituição do patrimônio em São Paulo: 1969-1987. São Paulo: Unesp, 2000.

${ }^{31}$ BENEVOLO, Leonardo. L'esigenza di conservare gli ambienti antichi non significa bloccare ogni iniziativa. Per conservare bisogna modificare la realtà, L'architettura cronache e storie, n. 21, p. 184, 1957.

32 Como afirma La Regina, as mudanças podem resultar em destruição (que deve, porém, ser mínima) que, contudo, não podem "alterar ilicitamente" a consistência física e formal dos bens. LA REGINA, Francesco. Come un ferro rovente, cultura e prassi del restauro architettonico. Napoli: Clean, 1992, p. 15. Lembrando, ainda, como o faz na p. 25 que: "a preservação, de bens culturais e ambientais na era moderna, não é uma finalidade encerrada em si própria, mas responde a um imperativo ético que deriva da convicção na ascese do conhecimento e na sua capacidade para servir de instrumento de uma constante readaptação do ethos às exigências da vida".

${ }^{33}$ BOITO, Camillo. Os Restauradores. Cotia: Ateliê, 2002. [Texto publicado originalmente em 1884].

${ }^{34}$ A esse respeito, ver por exemplo o texto de: WOLTERS, Wolfgang. Cosa Chiede lo Storico ad un Restauro. Bolletino d'Arte, n. 47, p. 123-124, 1988. Logo no início do artigo, o autor coloca a seguinte questão: "O que peço, como historiador da arte, a quem, como arquiteto ou como superintendente restaura um edifício? A 
resposta é fácil: que o edifício, ou seja, o documento, seja estudado com atenção e competência e transmitido de tal maneira que não comprometa o seu próprio valor como documento. A resposta é fácil, repetida, mas os fatos demonstram todos os dias que entre teoria e práxis quotidiana se abre um abismo".

${ }^{35}$ SCARROCCHIA, op. cit., p. 61.

${ }^{36}$ Resultando na Carta de Fortaleza de 1997 e no decreto no 3551 de 4 de agosto de 2000, que institui o registro de bens culturais de natureza imaterial e cria o programa nacional do patrimônio imaterial etc.

${ }^{37}$ PETRELLA, Antonio. John Ruskin e l'economia politica dell'Arte. Restauro, Nápoles, n. 91-92, p. 80, 1987.

${ }^{38}$ O papel da memória na conformação da identidade é tema da maior relevância e, apesar de ser um dos instrumentos utilizados neste texto, sua discussão não faz parte dos objetivos deste trabalho. Para uma aproximação ao tema e para referências complementares, v.: BERGSON, Henri, Matéria e Memória. São Paulo: Martins Fontes, 1990; BOSI, Ecléa. Memória e sociedade: lembranças de velhos. São Paulo: Companhia das Letras, 1995; O tempo vivo da memória: ensaios de psicologia social. São Paulo: Ateliê, 2003; CUNHA, Maria C. P. (org). O Direito à Memória - Patrimônio Histórico e Cidadania. São Paulo: Departamento do Patrimônio Histórico, 1992; HALL, Stuart. A questão da identidade cultural. Campinas: IFCH, 2003; HALBWACHS, Maurice. A memória coletiva. São Paulo: Vértice, 1990; JEUDY, Henri-Pierre. Memórias do social. Rio de Janeiro: Forense, 1990; La Machinerie patrimoniale. Paris: Sens \& Tonka; MATOS, Olgária. Memória e História. A Terceira Idade, v. 4, n. 6, p. 5-15, 1992; A cidade e o tempo: algumas reflexões sobre a função social das lembranças, Espaço \& Debate, n. 7, 1982; LE GOFF, Jacques. História e Memória. Campinas: Unicamp, 1996; MENESES, Ulpiano T. B. A História, cativa da memória? Revista do Instituto de Estudos Brasileiros, v. 34, p. 9-23, 1992; Patrimônio ambiental urbano: do lugar comum ao lugar de todos. CJ Arquitetura, n. 19, p. 45-46, 1978; NORA, Pierre. Les lieux de Mémoire. Paris: Gallimard, 1997; RICCEUR, Paul., La mémoire, I'histoire, l'oubli. Paris: Seuil, 2000. Agradeço Jean-Marc Basyn, Claudia dos Reis e Cunha e José Hermes Martins Pereira por várias referências e pela discussão de temas ligados ao campo. Outra questão importante refere-se aos aspectos psicológicos ligados à preservação, tema que tem sido pouco explorado em relação aos bens culturais. No que se refere à algumas comparações entre distúrbios gerados pela perda de memória para o indivíduo e destruições de monumentos e alterações da memória coletiva resultando em perturbações da identidade individual e social, v. CHOAY, Françoise. Riegl, Freud e i monumenti storici. In: SCARROCCHIA, op. cit., p. 455-465.

39 MÖRSCH, Georg. La realtà dei monumneti. Riflessioni sulla prassi di conservazione attuale. In: SCARROCCHIA, op. cit., p. 453.

${ }^{40}$ In: SCCARROCCHIA, Op. cit. Ver em especial p. 55-73; 575-578.

${ }^{41}$ Essa noção também possui larga genealogia. Já Bartolomeo Cavaceppi, no século XVIII (apesar de nas suas ações práticas nem sempre ser consciencioso e respeitoso em relação ao documento histórico), afirmava: "Não por outra razão se restaura, a não ser aprender com elas". Apud VLAD BORRELLI,Licia. Restauro archeologico. Storia e materiali. Roma: Viella, 2003, p. 83.

* Arquiteta. Doutora pela FAU-USP. Professora do Departamento de História da Arquitetura e Estética do Projeto da FAU-USP. 